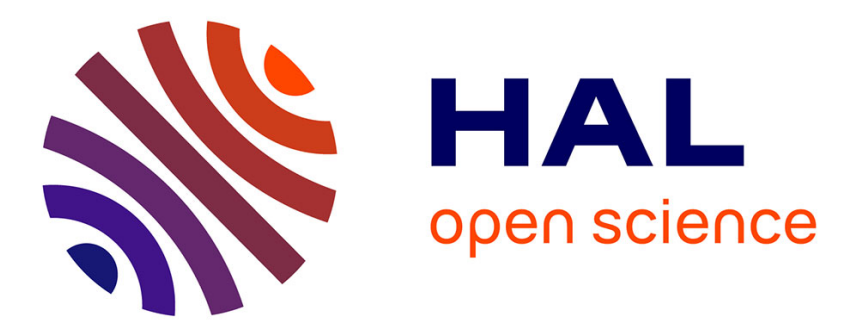

\title{
Probabilising the consumer: Georgescu-Roegen, Marschak and Quandt on the modelling of the consumer in the 1950s
}

\author{
Jean-Sébastien Lenfant
}

\section{- To cite this version:}

Jean-Sébastien Lenfant. Probabilising the consumer: Georgescu-Roegen, Marschak and Quandt on the modelling of the consumer in the 1950s. European Journal of the History of Economic Thought, 2018, The European Journal of the History of Economic Thought, 25 (1), pp.36-72. 10.1080/09672567.2017.1415949 . hal-02555394

\section{HAL Id: hal-02555394 \\ https://hal.univ-lille.fr/hal-02555394}

Submitted on 27 Apr 2020

HAL is a multi-disciplinary open access archive for the deposit and dissemination of scientific research documents, whether they are published or not. The documents may come from teaching and research institutions in France or abroad, or from public or private research centers.
L'archive ouverte pluridisciplinaire HAL, est destinée au dépôt et à la diffusion de documents scientifiques de niveau recherche, publiés ou non, émanant des établissements d'enseignement et de recherche français ou étrangers, des laboratoires publics ou privés. 
This document is a preprint of an article accepted for publication in the European Journal in the History of Economic Thought. It does not correspond to the published version (due to minor edits and rewriting of equations).

To cite this article :

Lenfant, Jean-Sébastien. 2018. Probabilizing the consumer. Georgescu-Roegen, Marschak and Quandt on the Modelling of the Consumer in the 1950s. European Journal in the History of Economic Thought, forthcoming.

Probabilizing the consumer:

Georgescu-Roegen, Marschak and Quandt on the Modeling of the Consumer in the 1950s

Revised draft: July 9 $9^{\text {th }} 2017$

Jean-Sébastien Lenfant

Université Lille 1, Clersé

Jean-sebastien.lenfant@univ-lille1.fr

Abstract

Probabilistic models of choice (between sure prospects) have become a standard modeling practice since the 1980s, notably through the widespread use of the Logit Multinomial Model pioneered by McFadden (1974). However, the idea to model consumer's behavior as a probabilistic behavior, hence accounting for some kind of behavioral instability in the pure theory

\footnotetext{
* Correspondence may be addressed to . Acknowledgments. I am most grateful to Philippe Mongin, Jean Baccelli, Ivan Moscati, and colleagues who have attended various presentations of this article for their constructive and insightful comments. I am sole responsible for any remaining error.
} 
of rational choice, dates back to the 1930s and led to significant investigations in the 1950s. It is the purpose of this article to confront three attempts by economists at developing models of individual choice that go beyond standard ordinalist utility theory through introducing principles of probabilistic behavior. We discuss first Georgescu-Roegen's neglected contributions to this subject, though he pioneered the definition of probabilistic preference in 1936 and came back on the subject intensively in the 1950s. We then present Marschak's (and his co-authors) attempts at axiomatizing a probabilistic model of choice in the same period. The third contribution studied is that of Quandt, who provides a more operational style of modeling. This set of contributions is discussed against a general background of transformations of the theory of rational behavior and of the methods proper to it.

Keywords: probabilistic choice theory, Georgescu-Roegen, Marschak, Quandt, measurement of utility, experimental psychology, consumer theory, threshold in choice, intransitivity, indifference.

JEL: B21, D11, D01

In the 1970s, Daniel McFadden devised a microeconometric model of stochastic choice, the Multinomial Logit model, which was soon adopted to 
model different situations of consumers' choice behaviors (McFadden, 1974; 2001). This kind of probabilistic modeling of consumer's choice-which is quite different from the attempts at modeling decision under uncertaintycomes after a series of attempts at representing the individual consumer as a probabilistic consumer. The purpose of this paper is to present some such attempts by economists in the 1950s

In 1950 the pure theory of consumer's behavior could appear as the most accomplished part of economic theory. With Pareto, Slutsky, Hicks, Allen and Schultz, Samuelson and Houthakker, and still many others, it had gone through a process of refinement, generalization and axiomatization, and it could rightly be presented as the major achievement of the discipline. Hereafter, I will refer to this whole set of contributions as representative of the ordinalist utility theory (OUT). ${ }^{1}$ Once consumer's choice theory had acquired its full legitimacy, it was much easier to embark on a critical examination of the limits of the theory as a positive model of behavior. Such criticisms would indeed put to the fore experimental evidence that subjects do not behave accordingly with the rules of rational behavior in different choice settings, or they would simply question the psychological foundations of the theory.

Actually, Hicks and Allen's 1934 achievement-an integrated presentation of demand, utility and preferences-was the starting point for a critical appraisal of the domain of validity and empirical tractability of the theory.

1 Samuelson (1950) showed that if a consumer abides by the strong axiom of revealed preferences, then theoreticians might as well use (ordinaly conceived) utility functions or revealed preference maps to model individual rational behavior. A number of issues about integrability and correspondence between the revealed preference approach and utility theory would indeed be solved within the following twenty years. The outcome of this was Chipman et al. (1971). None of this study, however, would jeopardize the strong unity of the theory of choice. 
Of course, the 'traditional' view on demand theory remained the backbone of most of the empirical work done on demand until the 1980s, stating with Henry Schultz (1938) masterpiece up to Deaton and Muelbauer (1980) textbook synthetizing research on demand systems.

In his celebrated article on consumer's theory, Georgescu-Roegen (1936) would devote a long section to introducing a probabilistic model of consumer's behavior that he regarded as an improvement over the Paretian model, accounting for the consumer's hesitation or ignorance when making choices and opening to a dynamic theory of demand. Earlier on, Gilboy (1930; 1931) had underlined that the pure static theory of choice was intractable because any statistical attempt at deriving demand curves would induce time and hence changes in the demand schedules. Also, following a more destructive purpose, Friedman and Wallis (1942) would criticize the Paretian theory of choice for being inadequate to any empirical investigation (see Lenfant, 2012a).2 Apart from those few challenges, no significant appraisal of the pure theory of consumer's choice would take place before the beginning of the 1950s. As Georgescu-Roegen (1950, 125) puts it: “Today, it seems that even the nonmathematical economists no longer question the results of this chapter of mathematical economics [the ordinalist view of the Paretian and Samuelson's reformulation in the Foundations] and that the conclusion that the law of demand is a uniquely defined relationship between prices and quantities is a soundly enthroned economic law".

On the contrary, the 1950s would witness a number of attempts at dealing with the imperfections of consumers as utility maximizers, which in turn led

\footnotetext{
${ }^{2}$ Friedman (1949) would follow this line in his interpretation of the Marshallian demand curve.
} 
to the idea to represent their behavior through a probabilistic model (later called stochastic model of choice). This search developed partly under the impulse of a growing literature on experimental psychology dealing with the rationality of choices (Lenfant 2012b). Many experiments on individual preferences, on transitivity, on binary-choice, on learning, were carried out (Moscati, 2007), and some psychologists and economists were involved in collaborative projects to study individual behavior (see Heukelom, 2014). More, the nascent field of behavioral economics - actually the application to decision and choice models of the methods of experimental psychologywas fostered by experimental work on the expected utility maximization hypothesis that had been advanced by von Neumman and Morgenstern (1944).

Compared with the abstract and deterministic model of consumer's behavior, which was not easily connected with experimentation-also in its revealed preference form-, expected-utility seemed to be much more amenable to experimentation in a laboratory environment and thus led to experimental work and theoretical discussion (notably Friedman and Savage (1948), Marschak (1950), Mosteller and Nogee (1951), Friedman and Savage (1952), Edwards (1953)). To some economists, the main advantage of expected utility theory was to convey a measurable concept of utility, and the question was floating in the air about the overall unity of the different representations of individuals' rationality and how far the quest for a utilitarian view on economic motives and evaluations was to prevail on the understanding of market behaviors. 
It is our thesis that, in many respects the different attempts at probabilizing the consumer in the 1950 s can be seen as attempts to address the questions of the foundations of the theory of rational choice, its grounding in fairly descriptive psychological assumptions, its connections with choice among uncertain prospects. This period of transformations did not result in the setting up of a new standard in the modeling of rational choice; however, it contributed to extending the domain of applicability of the theory of the consumer.

The purpose of the present study is to provide a general view on different attempts by economists at formulating a probabilistic version of individual choice in a non-risky environment, focusing on the contributions of Georgescu-Roegen, Marschak and Quandt. ${ }^{3}$ The probabilistic choice theories discussed in this paper are not expected utility theory and are often presented as an alternative to it; they are theories in the tradition of riskless choice while at the same time involving probabilistic concepts in some way, and they are viewed as improving the theory both conceptually and operationnaly.

The comparison between different models of probabilistic choice will be linked with the general contextual background. Broadly, the claim is that the background as we see it opens up to different strategies for modeling choice. On the one hand, there is the internal constraint for thinking about rational behavior within a unified theory, connecting choice theory and decision

\footnotetext{
${ }^{3}$ It is a complex story and we do not pretend to deal in depth with many issues that would deserve a separate investigation, such as the links with experimental psychology or the internal debates about the meaning of the axiomatics of expected utility. On both topics, see Moscati (2007), Lenfant (2012b), Heukelom (2014) and Moscati (2016).
} 
theory. On the other hand, there is the external interest for taking account of the contributions of experimental psychology or simply to introduce principles of folk psychology, thus leading potentially to a collection of models of choice adapted to different behavioral hypotheses affecting individual choice.

The first section (1. Challenging OUT from inside) deals with the context of the theory of choice in the 1940s and 1950s. The aim of this section is to focus on the elements of criticism that point out the internal weaknesses of the theory regarding preferences, indifference, uncertainty, utility measurement. It deals also with the disruptive effect of expected utility theory (EUT), which was seen by some economists as challenging the standard model of choice, calling for a generic view on rational behavior. Section 2 will focus on the growing influence of experimental psychology of choice and decision on economists (2. Towards psychological foundations of probabilistic choice). Even if it was limited to a small arena of skilled mathematical economists and behavioral scientists, it provided a set of concepts and ideas that were to be applied, under different guise, to the probabilistic theory of choice. The rest of the article presents three alternative models of probabilistic choice. Section 3 presents Georgescu-Roegen's main model of probabilistic choice (Georgescu-Roegen, 1958) and relates it to other writings by the same author (3. Georgescu-Roegen's axiomatics of the threshold in choice). Notably, we show that Georgescu-Roegen's analysis mixes a psychological foundation of choice with an axiomatic approach. Section 3 deals with Marschak's axiomatics of binary choices (4. Marschak's binary-choice model). It is argued that Marschak's agenda is to explore the possibility to arrive at some 
cardinalist representation of utility. Section 5 deals with Quandt's contribution to the issue, which is conceived of as a set of operational models of choice and demand (5. Quandt's models of probabilistic consumer). Section 6 concludes (6. Concluding comments). ${ }^{4}$

\section{Challenging OUT from inside}

The accomplishment of ordinalism in demand theory culminated with the HicksAllen (1934) assertion that the whole theory of economic behavior should be derived from the knowledge of indifference curves. As Georgescu-Roegen (1958) would make clear, the idea to rely on indifference curves rather than to begin directly with statistical demand curves is mainly that on the basis of the hypothesis of rational agents (non intersecting convex to the origin indifference curves) a complete set of demand curves can be derived from a reasonable amount of information about indifference. The debate on the most satisfying set of assumptions in order to derive indifference curves was then on the tracks when Samuelson set up the revealed preference approach (Samuelson, 1938). In the meantime, between 1934 and the

\footnotetext{
${ }^{4}$ The present research being a first step in a little known episode of the theory of choice, it is not based on archival material and instead aims at presenting three different ways to implement a probabilistic interpretation of the consumer's behavior, trying to relate them with the background of discontent with OUT after WWII. Certainly, this first study should be a starting point for more specific inquiries into Georgescu-Roegen's and Marschak's archives.
} 
completion of Samuelson's program (Houthakker (1950), Samuelson (1950)) some arguments were already leveled out against OUT. ${ }^{5}$

Firstly, a number of internal critics would challenge the coherence of the theory and the set of hypotheses on which it is grounded, pointing out the need for more satisfactory psychological foundations. Secondly, EUT provided a model of rational behavior that triggered some reflections on the relative merits of each model (OUT vs EUT), fostering a search for a general axiomatics of choice encompassing the risky and the riskless models as specific cases.

\subsection{Challenges to the internal consistency and operationality of OUT.}

In the 1930s, and especially after Hicks and Allen (1934) joint paper, the theory of choice was still a subject of debates, even though it was undoubtedly the starting point for the formation of an orthodox theory of choice and demand. A careful reader could identify that the two parts of their paper were indicating two different ways to look at the foundations of the theory of choice, Allen voicing his preference for the non-integrable case while Hicks would clearly favor the integrable case (Hands, 2006 and 2011, Chipman and Lenfant, 2002). Also, the idea that economists should get rid of a measurable concept of utility was not easily accepted. Actually, in the 1930s economists had not inquired extensively the relationship between utility and preferences. The preference-indifference approach was usually associated with the acceptance that utility is not a measurable magnitude. Frisch's ventures into the

\footnotetext{
5 Actually, the outcome of the Samuelson endeavor was that the use of the indifference-curve approach was eventually warranted as a theoretical construct, but not as an empirical construct (Lenfant, 2012a).
} 
subject remained rather isolated but showed also that a complete axiomatics of preferences needed completion (Frisch, 1926 and 1932). ${ }^{6}$

Among the notable contributions to the pure theory of the consumer, GeorgescuRoegen (1936) was the first to address in depth the issue of integrability and to relate its economic meaning with the issue of transitivity of the indifferencepreference relation. As a second step in his inquiry, he explored the case when a consumer is unable to tell at once which of two stimulus is the greatest, thus showing an area of doubt when asked to choose between two alternatives: a psychological threshold. To model such a situation, he introduces the probability $p(x, y)$ that a stimulus $x$ be considered greater than $y$ when the agent is presented several times a choice between $x$ and $y$ (Georgescu-Roegen, 1936, 569). Interestingly, Georgescu-Roegen's grounds this probabilistic presentation in psychologists' notion of least perceptible differences, which had been introduced into American psychological research by Fullerton and Cattell (1892). To Georgescu-Roegen, only if the consumer was allowed an extensive time to select goods would the static theory apply as a limit case. ${ }^{7}$ Georgescu-Roegen did not explicitly define preference for $x$ over $y$ as $p(x, y)>1 / 2$, even though it is implicit in his reasoning. Georgescu-Roegen's innovative treatment of the theory of the consumer

6 The analytical examination of the conditions under which a system of axioms about the structure of individual preferences could be represented through a utility function was not addressed before Wold's 1943/1944 synthesis of demand theory, whose diffusion was rather confidential. It remained uncompleted until Debreu (1954), who gave sufficient conditions for representing a system of preferences with a real-valued utility function.

${ }^{7}$ In view of Georgescu-Roegen's later considerations on time (Bobulescu, 2017) in economics, which were to be central to his abandoning of the neoclassical framework, the 1936 paper lays the foundations for an opposition between a static modeling of choice against a dynamic one. 
was quite ignored and almost never mentioned before 1950. It seems that no economist in this period ventured to discuss the concepts of utility or preference as expressed through a probabilistic treatment of the consumer's behavior. Armstrong (1939), for instance, tried to erect a destructive criticism of the theory of utility held by the Lausanne school upon the principle that the consumer exhibits intransitive indifference. The reason for this, he said, stems from our inability to make accurate judgments about our want-satisfaction estimates. However, he did not even consider that those inaccuracies should be treated as a probabilistic variable. ${ }^{8}$ He does not seem aware that the construction of utility makes sense through repetition of similar choice situations.

An older and more trivial trend of criticisms stresses that the utility function (and the underlying preferences) is highly unstable over time. This objection has been addressed to the theory on many occasions and from many different traditions of analysis. It is common in the Chicago tradition: Wallis and Friedman (1942) or Stigler (1948) tended to consider that tastes' variability is the Achille's heel of the pure theory of the consumer. This idea will come back in the 1950s mainly from the psychologists' side. ${ }^{9}$

Even Georgescu-Roegen, coming back on his earlier work, would judge that:

\footnotetext{
${ }^{8}$ See especially Armstrong (1939, 462 and sq).

${ }^{9}$ From Katona $(1953,313)$, we are inclined to think that every psychologist would contest the very idea of a given preference pattern before choice: "Any contradiction of a theorem derived from utility theory can always be attributed to a change of tastes, rather than to an error in the postulates or logic of the theory" (Katona, 1953, 313). More generally, it is a fact that preferences is not a concept of psychological theory. It was imported only to psychology in the 1950 s.
} 
"The usual attitude adopted by different writers on the subject, including the author, was to investigate, as a next step, the shape of the indifference varieties. But on second thought, this appears to be rather a rash logical procedure. For the above postulate cannot be transformed into a useful theoretical tool without further qualifications" (Georgescu-Roegen, 1950, 126)

In the 1950 s, the idea to build an operational model of choice by taking account of consumers' hesitations or discriminal limits would be more common in some works done at the boundary of decision theory and psychology.

\subsection{Expected utility theory enters the scene.}

The interest for alternative models of riskless choice in the 1950s is not independent from the debates that followed Von Neumann and Morgenstern's Theory of games and economic behavior (1944) and their axiomatization of choice among risky prospects, namely Expected Utility Theory (EUT).

From the reading of the comments and reactions of economists working in the field of demand theory and welfare analysis - independently of criticisms by eminent economists such as Samuelson, Wold, Malinvaud-EUT aroused a number of questions on the relationships between choice under uncertainty and choice among sure outcomes: Is EUT a broader model of choice from which the theory of choice between sure prospects is just a limit case? Or else, are both theories to be taken as complementary models of choice, depending upon a common mathematical structure? Should we modify the traditional theory of choice in order to introduce 
more structure into it and implement some sort of utility measurement, thus putting both theories on an equal footing?

It is beyond the hopes of this article to disentangle all the intricacies of the literature of this period (circa 1945-1960), which testimonies a burgeoning of models of choice and utility (Houthakker, 1961). Our more modest task is to identify to what extent a probabilistic model of choice could be seen as a possible extension of the traditional theory of choice, addressing some issues about the relationships between OUT and EUT.

The expected utility hypothesis shows that on the basis of a series of axioms on the ordering of lotteries (uncertain outcomes or consequences), the individual's preferences over lotteries can be represented by a utility function, which has an expected utility form. As a consequence of the axioms of the theory (axioms about preferences over related lotteries), the preferences of individuals over uncertain prospects can be represented by linear utility functions in the probabilities. Of course, any positive transformation of such utility functions will represent the same preferences (Arrow, 1951c, 10).

A brief reminder of the axiom of independence will prove fruitful to make a comparison with the probabilistic theory of choice. Indeed, the qualitative difference between the expected utility function and any order-preserving utility function stems from the fact that EUT assumes some mathematical structure upon uncertain alternatives. In addition to the continuity axiom (a small change in probabilities does not change the preference ordering between lotteries, ruling out lexicographic orderings), the axiom of central importance is the axiom of independence. A 
preference relation on the space of lotteries $\mathcal{L}$ satisfies the independence axiom if a mixture of each lottery with a third one does not change the preference ordering. The central importance of the independence axiom in EUT has been much debated by the end of the 1940s and the beginning of 1950s (Samuelson, 1952; Malinvaud, 1952; Wold, 1952; Georgescu-Roegen, 1954; see Moscati, 2016). In OUT, the preference pattern is defined over a set of alternatives (the consumption set) for a given context of choice and consumption, i.e. some other quantities of goods consumed are given and assumed not to change for the consumer. Otherwise, the whole set of indifference curves might change (except for those goods that are independent from the one under consideration). On the contrary, EUT assumes that the set of other lotteries (or other possible outcomes) does not affect individual's preferences. This is certainly more than an anecdotal difference between both theories. Thus we may wonder whether the development of a probabilistic theory of choice will be affect this qualitative difference, allowing different contexts of choice for the consumer to be merged into one single representation of tastes.

Some economists would reflect on the relative merits of OUT and EUT. The main idea is that uncertainty is a pervading phenomenon. Arrow (1951a), for instance, notes that: "it is no exaggeration to say that every choice made by human beings would meet this description [that consequences are unknown] if attention were paid to the ultimate implications" (Arrow, 1951a, 404). Nevertheless, it seems that some theorists have seized the opportunity given to them by EUT to throw away the traditional setting. To Alchian $(1953,34)$ "even the act of purchasing a loaf of bread has an element of uncertainty". Even more dramatic, Armstrong seems to beleive that the coming out of EUT is giving the last blow on OUT : "A theory that irretrievably 
breaks down when even a trace of uncertainty is present is not even serviceable as a preliminary hypothesis" (Armstrong, 1948, 1). Unfaithful criticisms kept apart, it is clear that the hypothesis of absolute certainty of outcomes seems to be uncomfortable, and it is felt that some source of contingency might fruitfully be introduced into the model. Uncertainty might be not a characteristic of the external world but a consequence of our inability to take account, all-at-once, of all characteristics and circumstances of choice, or of the facts that choices are done within different contexts. This way of extending the conventional model of choice goes along a trend of criticism from experimental psychologists in the 1940s and 1950s. ${ }^{10}$

Before to look at the influence of psychologists on the understanding of alternative models of choice in economics, a general comment is necessary. On the one hand, EUT could appear as having the advantage to generate more precise preference schemes, with potentially important effects for welfare analysis. On the other hand, EUT does not generate a demand theory to the degree that OUT does. There is no equivalent to Slutsky symmetry, homogeneity, income and substitution effects. Here, we must consider that the confrontation of both theories leads us back to a more fundamental issue about what should the basic foundations of economics $d o$, and not solely on what they should be. The question was revived by Friedman's 1953 essay on positive economics. If one considers that economics is first a science that studies market coordination and that rational behaviors proceed from different

\footnotetext{
10 An indirect effect, maybe, of the comparison induced by some economists between OUT and EUT is a way of presenting consumer's theory as a generic model of rational choice adapted to every situation of choice. Alchian $(1953,32)$ for instance, argues that the model should deal with not only with marketable commodities but also with patterns of actions (a trip to Europe, getting married). Neither Pareto nor Hicks did entrust consumer's theory with such a purpose (see Lenfant, 2012a). This inflection was probably already on the way in the Chicago style of reasoning, but it was probably strengthen on this occasion.
} 
market structures, then economists should have at their disposal a theory of choice that provides a pattern of analytical statements about demand behavior. If instead one considers that economics consists in applying a general principle of rational choice to a variety of situations and to compare the welfare properties of different situations, then having a general theory of rational choice (and of welfare) is of primary importance. Consequently, the relative importance of OUT compared with EUT is a matter of personal agenda. Certainly Georgescu-Roegen, in addition to his desire to ground choice theory on a more realistic psychological background also wanted to preserve some of the implications of OUT. On the contrary, Marschak could be seen as someone who puts to the forefront individual choice and utility measurement. Whatever the personal interpretation of such or such economist, those interested in choice and decision theory in the 1950s could consider that probabilistic models of choice would help comparing both theories. Houthakker's statement in his 1961 survey offers a good synthesis of the stakes, making probabilistic choice theory a general-purpose device:

\footnotetext{
"It may be useful to point out that the traditional theory of consumer's choice is not, as is often believed, a theory based on the assumption of certainty. What is assumed is that an individual can rank all objects available to him in order of desirability. Whether the results of obtaining these objects are certain or not is irrelevant, and in principle the classical theory applies just as well to lottery tickets as to any other object. What the new approach just referred to does contribute is a systematic analysis of probabilistic aspects on the formation of preferences. Such an analysis may no doubt be useful in contexts other than that of consumption." (Houthakker, 1961, 725) ${ }^{11}$
}

11 Interestingly, Houthakker (1961) underlines the relationship between the theory of risky decisions and the probabilistic extension of OUT: 


\section{Towards psychological foundations of probabilistic choice}

The purpose of this section is to put together a list of arguments scattered through economic literature, that have been raised in favor of a modification of the theory of choice. Some open naturally to a probabilistic reformulation of the theory. Even if many arguments raised in favor of a probabilistic model of choice are borrowed from the work of psychologists, it is done, most often, without references to specific results in psychology. Some of the concepts or ideas borrowed from psychology manifestly overlap or will appear redundant. As it is, it displays an intensive collective interest for implementing better psychological foundations in the theory of choice, among authors who were not following exactly the same agenda. Peculiar attention will be given to Georgescu-Roegen, Quandt and Marschak in order to point out there overall attitude towards set of experimental evidences, psychological concepts and mechanisms at their disposal.

Psychologists have played an important role in shaping the development of a probabilistic theory of choice. In the late 1940s, the interest of psychologists for decision theory and then for the theory of choice was fostered by a number of experiments aimed at testing properties of rational choice theories. ${ }^{12}$ The most wellknown work in this respect is Mosteller and Nogee's experiment on EUT (Mosteller and Nogee, 1951), which was instrumental in calling attention of some economists to the methods of psychologists in the field of choice analysis and showed how EUT

12 Meanwhile, the revealed preference approach reinforced the emphasis on observable data, "gradually transforming utility to an essential component of empirical research." (Houthakker, 1961, 713). 
was amenable to test (Moscati, 2007). Of course, we are not suggesting that economists were suddenly converted to EUT because of some experimental work on it. Although total quantity of experimental research is very small compared to recent years, it was an important and growing literature. This set of literature is the starting point for the penetration of psychological arguments into the methodology of choice and decision theory into economics, and some economists have been collaborating with psychologists and behavioral scientists in this period (R. L. Davis, 1954; Edwards, 1954; Moscati, 2007 and Heukelom, 2014). ${ }^{13}$

There has been also, through interactions between psychologists and economists, a progressive acceptance of experimental work in the field of the theory of choice (Arrow, 1958). In this context, economists interested in the theory of choice became permeable to the idea of treating consumer's choice as probabilistic data. In the 1950s, psychologists were familiar with implementing some kind of probabilistic treatment on the experimental data. In the $1920 \mathrm{~s}$, Thurstone had devised a method, The Law of Comparative Judgment, to deal with subjects imperfect discriminal capacities (Thurstone, 1927; Gigerenzer, 1990). By the end of the 1940s, when some psychologists began working on the theory of rational behavior, they came in also with a toolbox of concepts and practices about measurement, scaling, perception of small differences, levels of aspiration that were to be applied to rational choice theories, and they did not assume that agents had a capacity to manifest coherently a set of indifference curves.

\footnotetext{
${ }^{13}$ One can mention a short list of scholars that would participate actively in the theory of choice and decision in economics within the period (circa 1945-1960) and that eventually contributed to the anchoring of experimental psychology and mathematical psychology at economic theory: Edwards, Katona, Mosteller, Coombs, Davidson, Davis, Estes, Lewin, Siegel, Simon, Stevens, Suppes, Luce.
} 
In their experimental analysis, Mosteller and Nogee (1951) treat subjects' answers as probabilities, and a number of other experiments would use a similar standard methods. Thus, from the standards of experimental psychology, the theory of risky and non-risky choices needed to be interpreted as a probabilistic model. For instance, Davidson, Suppes and Siegel (1957) point out that: ${ }^{14}$

"Most models for theories of decision are naturally interpreted as dealing with preference and indifference, while the protocols provided by behavioristic experiments concern decisions. Choices are particular responses with a date; preference and indifference are rather dispositions which characterize an organism over a span of time. This raises the question how choices are to be related to preference and indifference." (Davidson, Suppes and Siegel, 1957, 16)

Now, this probabilistic model of choice could be linked with different views as to the kind of significant contextual influences to be taken into account in the modeling strategy. A first theme of inquiry is that of transitivity. Probably the first explicit definition of probabilistic preference is that of Papandreou (1953 and 1957) and Papandreou et al. (1957) (see Moscati, 2007, 383-384). It was conceived from the outset as a test of a probabilistic interpretation of choice among sure prospects. Instead of testing an al-at-once property of transitivity, the test is on the probabilistic statement that $p(x, y)>1 / 2$ and $p(y, z) \geq 1 / 2$ implies $p(x, z)>p(y, z){ }^{15}$ This theme is

14 In a similar vein, Wold pointed out that the independence axiom shall not be acceptable in a repeated choice among uncertain outcomes (Wold, 1952, 663)

15 Papandreou's experiments consisted in choosing one activity in a binary choice situation (with two activities). More than 80 percent of the answers were in 
echoed in various works in economics (Georgescu-Roegen (1936, 1950, 1958), Marschak (1955)) who provided different definitions. A second theme of inquiry at the juncture between the pure theory of choice and experimental psychology deals with the role of learning in the temporal process of choice. The distinction seems to be necessary for a situational definition of rationality. The hypothesis that individuals are able to order once and for all the set of possible alternatives to which they might be confronted is said to be contradictory with the principle of selectivity of human behavior (see Katona, 1953, 311). An implication of learning processes for any psychologist is that subjects are likely to change their representation of preferences and also to adopt some kinds of information gathering behavior. This theme is present in Georgescu-Roegen's work and in Quandt (1956) A third and connected theme of inquiry is that of levels of aspiration. They may affect the determination of preferences more than the definition of indifference. The concept captures the idea that in a decision context, individuals tend to define for themselves the goal that they will try to achieve. Individuals' preferences cannot be established as long as levels of aspiration determining the goals to be achieved have not been stabilized. The preference relation between two prospects $A$ and $B$ cannot give us any indication about the future behavior of a subject if "at different times $A$ and $B$ are seen in different contexts - because of changed external conditions or the acquisition of new experiences-we may have to distinguish among several dimensions" (Katona, 1953, 316). This idea of a contextual analysis of economic

accordance with the definition of probabilistic transitivity. Actually, Moscati (2007) points that no statistical test for rejecting the null hypothesis could be carried out. 
behavior will surface in Quandt (1956). Those different themes are dealt with by Georgescu-Roegen, Marshcak and Quandt through various psychological notions.

\section{Sensorial threshold and hesitation}

The sensorial threshold refers to the fact that human beings are not perfectly able to discriminate stimuli that differ only to a very slight degree, and it was introduced in psychology by Fechner and further developed along the tradition of psychophysics, notably with Fullerton and Cattel (1892) and later on with Thurstone (see Lenfant, 2012b). In economics, it is said that Pareto alludes to the threshold on some occasion, but its first serious introduction is to be found in Georgescu-Roegen (1936) (who new it from Fullerton and Cattell), who would develop upon this idea in the 1950s (Georgescu-Roegen, 1950 and 1958). ${ }^{16}$

The gist of the idea is that there is an area in which the consumer is not able to assert which of two stimuli is the greatest. He may hesitate. But physical

${ }^{16}$ On this topic, we must mention Duncan Luce, a very influential mathematical psychologist, who repeatedly came on the subject of discriminatory power, that he linked with the Fechnerian tradition of psychophysics (see especially Luce, 1959b and Luce and Edwards, 1958). We cannot discriminate adjacent weights, for instance, and nevertheless, we can differentiate a greater difference. Intransitivity thus "reflects the inability of an instrument to discriminate relatively to an imposed discrimination task" (Luce, 1956, 179; see also Luce (1959, 145-146)). Indeed, following the idea that individuals do have an imperfect power of discrimination (represented through the notion of just noticeable differences), a specific kind of scaling of individual preferences could be obtained through an adequate set of constraints on the probability to choose one element in a set of alternatives. A few words are in order concerning Luce's contributions to the field of probabilistic choice (Luce, 1956; Luce, 1958; Luce, 1959; Luce and Edwards, 1958). We have decided not to devote a full section on Luce since his contributions, important as they are for the subject at hand, are not oriented towards a reformulation and extension of the traditional model of choice and are motivated by psychological concerns (notably measurement issues). Nevertheless, Luce's work is of course at the core of the ferment of ideas of the 1950's and he contributed much to the import of concepts and methods of psychology into economics. For a presentation of Luce model (especially the axiom of choice) and a discussion within the history of random utility, see De Palma and Thisse (1987) and Lenfant (2012b). 
scales of measurement can help us to make choices when sensorial scales are hopeless. In a sense, Georgescu-Roegen (1936) indicated a potential effect of the threshold in categorizing goods according to the effective sensibility to the threshold in choice, that is, to the degree of potential indifference between bundles. In the case of staple commodities, for instance, "that are more regularly consumed and consequently experimented with longer" (Georgescu-Roegen, 1936, 587), the preferences are not liable to significant changes, thus the influence of salesmen in those goods is small. The more the consumer is allowed to have time to experience with goods, the more his threshold will shrink. As far as we know, GeorgescuRoegen $(1936,569)$ is the first to point out that hesitation is an observational parameter that the theory might take into account.

\section{Ignorance and learning}

The idea that the agent will gain information and learn what are the best choices in different situations is commonplace, even though it is not always the main argument for deriving a probabilistic model. This process can start from a situation of ignorance. It plays a significant role in Quandt (1956). It does mean that at a certain moment of time, the consumer is "incapable of stating whether he prefers $A$ to $B$ or $B$ to $A$ or whether he is indifferent between them" (Quandt, 1956, 509). Actually, ignorance can be only a provisional state of mind. If learning implies that the final mapping of indifference will depend upon the experience of the individual, there is then an element of "irreversibility" in consumption behavior. Duesenberry (1949) and Modigliani (1952) had identified an irreversibility of this kind. GeorgescuRoegen (1950) would also advocate for introducing an hereditary component in a 
dynamic theory of choice that would stem from all the internal changes due to our own experience. Otherwise, "you just have to represent a completely static economic world, but then you do not need indifference curves, no more than supply and demand curves" (Georgescu-Roegen, 1950, 128). ${ }^{17}$ A random behavior can stem from the agent's acquaintance with the fact that through a mixed strategy, he can obtain an intermediate bundle in the mean or that ignorance of his true preferences leads to a randomization of his choice. This argument is to be found in Marschak (1955) and Quandt (1956, 510): “The desire for variety may well be part of the consumer's 'tastes",. 18

\section{Multiple characteristics of goods.}

In another experiment on intransitive choices, May $(1954,8)$ pointed out that commonly "the alternatives of interest to the economist are typically commodity bundles, i.e. vectors whose components are quantities of goods and services of various kinds. Even an individual commodity is really a vector of its specifications and other attributes such as its price". This idea would spread in the literature: It is mentioned in Simon $(1955,108)$ and it would become a central argument in the probabilistic model of choice developed by Quandt (1956). Actually, Quandt builds his model of probabilistic choice upon the idea that the set of characteristics to be

${ }^{17}$ Georgescu-Roegen (1950) tries to provide a model for constructing indifference curves when the consumer takes account of past experience. Among other scholars, Luce (1959b) would again discuss the influence of learning in relation with the axiom of choice. Learning is also a central theme of Simon's (Simon, 1955) reconstruction of the theory of rational behavior.

${ }^{18}$ A related issue is whether what is called random behavior is a conscious strategy of the agent or if it is a projected interpretation of the theoretician. It will always be difficult to disentangle conscious random behavior from errors of choice on the part of the consumer, and from errors in the experimental setting. 
considered is changing from time to time, according to external circumstances. This may explain intransitive behavior, and more fundamentally, the strategy of the consumer in relation to the cost of acquiring knowledge.

All in all, we are now in a position to come to the presentation and discussion of three models of a probabilistic consumer. Mainly, one of the stakes is clearly to be able to derive a testable model, even though this is certainly not the only objective. As Simon would put it:

"Although the (probabilistic) theory weakens the requirements of consistency in preference, it is empirically testable, at least in principle. Conceptually, it provides a more plausible interpretation of the notion of 'indifference' than does the classical theory" (Simon, 1959, 261-262)

\section{Georgescu-Roegen and the axiomatics of the threshold in choice}

Georgescu-Roegen has constantly questioned the theory of consumer's choice since his contributions to the debate on integrability (Georgescu-Roegen, 1935 and 1936) until the end of the 1950's (Georgescu-Roegen, 1950, 1954, 1958). He already tackled a probabilistic approach to demand in Georgescu-Roegen (1936) and came back on the subject once again in Georgescu-Roegen (1958). In the present study, for reasons of comparability, I will refer to the 1958 model (an axiomatized presentation of the model of 1936) and refer to other articles for introductory and supplementary comments.

His interest for the theory of choice is clearly motivated: 
"The raison d'être of the theory of choice as a chapter of economics is above all the simplification it brings to the theory of demand... The indifference map is not only the simpler but of the simplest type possible: the curves do not intersect and, what is more, all display the same shape-uniformity. ... Thus, because of the simple structure of the indifference map, considerably fewer observations are needed to obtain an approximate drawing of this map by experiment than would be necessary for the map of all demand curves." (Georgescu-Roegen, 1958,157).

Georgescu-Roegen would always link the improvement of the model with a search for a better empirical imprint: "What we aim at is a theory molded on a type of individual that really exists and not on a 'necessary and sufficient' one" (GeorgescuRoegen, 1936, 585). The main outcome of the 1936 article is that introducing a probabilistic model of choice leads, somewhat not unexpectedly, to a "demand penumbra", that is a stochastic distribution of choices associated to each price.

The main flaw of the pure theory of choice, as Georgescu-Roegen sees it, lies in the question of integrability, and more precisely, in the importance of the property of transitivity which turns out to be the most important for the economic meaning of the concept. From a methodological point of view, Georgescu-Roegen subscribes to the idea that introspection is a necessary step in the development of the theory of choice, since actual experiment cannot easily be carried out. He advocates that the theoretician shall state explicitly the mental experiments, linked with the nature of indifference, that go "beyond the usual degree of accuracy of our measurements" (Georgescu-Roegen, 1936, 547, fn3). Otherwise stated, we can reasonably read Georgescu-Roegen's venture in the field of choice theory as an attempt to make 
explicit the set of assumptions necessary for an operational definition of indifference curves. $^{19}$

Particularly, the 1958 article provides an axiomatic presentation of the system of preference attached to the principle of a threshold in choice and clarifies the proper role of the sensorial threshold in the model.

Actually, the consumer can rely on two complementary systems of information to compare bundles (i.e. stimuli), which are kept separate from each other. On the one hand, there is a psychological information, associated to the sensorial abilities of the agent; on the other hand, there is a physical information, involving some cognitive process and, associated to it, some objective measurement of the qualities of the different alternatives. This second, physical, scale of measurement is very important since very often, choices are made on the basis of this scale only:

"The individual's behavior appears therefore as a resultant of two different types of measurement: a physical one, which is supposed to tell him the exact amounts of commodities and a psychological one, which is his possibility of comparing satisfactions. The fact that these two kinds of measurements are both involved in the present scheme constitutes an important point in the problem." (Georgescu-Roegen, 1936,572, fn6)

In the following, $p(A, 1$ is the probability that $A$ be chosen over $B$ as the result of a binary choice between two points $A\left(a_{1}, a_{2}, \ldots a_{n}\right)$ and $B\left(b_{1}, b_{2}, \ldots b_{n}\right)$. The following terminology (and notations) will be used:

\footnotetext{
19 "We can arrive in this way at the formulation of a necessary and sufficient set of assumptions for handling the problem, and thus obtain a kind of measure of the extent to which our mental experiment may diverge from a similar actual investigation. For maintaining further this parallelism between the mental and actual experiment, the formulation of our postulates in such a way as to outline in a straightforward fashion the corresponding physical investigation is undoubtedly the most advisable procedure." (Georgescu-Roegen, 1936, 546-547).
} 
Strong preference

Preference

Weak Preference

Complete Indifference

Indifference
$A I \boldsymbol{I}$ lf $p(A, \boldsymbol{L}$

$A \boldsymbol{H} \boldsymbol{i f p}(A, B$

$A \pi \boldsymbol{B}$ if $p(A, \boldsymbol{B})=$

$A / B$ if $p(A, B$

$A i B$ if $p(A, B)$

Broadly, the reader might consider that the terminology is designed to avoid any discontinuity in the description of the probabilistic model. The axioms of the binarychoice theory are as follows.

Axiom GR1: The result of a binary choice between two points $A\left(a_{1}, a_{2}, .\right.$. and $B\left(b_{1}, b_{2}, \ldots b_{n}\right)$ is either $A$ or $B$, i.e. the consumer can always choose, and

$$
p(A, \boldsymbol{B})+p(\boldsymbol{B},
$$

Axiom GR2: If $A \geq$. in the sense that at least one component of $A$ is greater and none is smaller, then $A I L$ (strong preference)

This is a fundamental axiom in the threshold model, expressing the "threshold in choice" as something different from the "sensorial threshold". It means that "a rational individual will always choose $A$ if $\mathrm{A} \geq \mathrm{B}$, however small the difference $A$ $B . "$ (Georgescu-Roegen, 1958, 159) Otherwise stated, strong preference is not solely the result of the consumer's senses: It can result also from "outside scales" (Georgescu-Roegen, 1958, 159). ${ }^{20}$

\footnotetext{
${ }^{20}$ The axiom also implies that there is no saturation (for any good in the commodity space) and the agent get's the bare necessities in any good.
} 
As we understand it - given that Georgescu-Roegen's line of thought is windingthe gist of the argument may be summarized as follows. Our choices are not only the result of sensorial knowledge (such knowledge should indeed suppose some kind of memory and familiarity with the objects and quantities consumed) but also the result of what we may call a cognitive knowledge (i.e. the conscious knowledge that some physical characteristic is greater in $A$ than in $B$ "in a world where quantities exchanged are determined with the aid of physical instruments"). It seems to us that this can be linked with the kind of knowledge that experimental psychology added to economics in the 1940s and 1950s. Even if this assumption is specific to the model of the threshold in choice, everything happens as if the sensorial order had become of secondary importance in a world where most of our actions are embedded into physical measuring scales. ${ }^{21}$

Axiom GR3: The function $p(X, 1$ is continuous in $X$, except for $X=A$, where it can have any value in the closed interval $(0,1)$ (Georgescu-Roegen, 1958, 160).

Axiom GR4: If $A \leq$ then $p(A, \mathrm{C}) \leq p($, the equality sign holding only if $p(A, \boldsymbol{C})$ or $p(\boldsymbol{B}, \boldsymbol{C})=$

This axiom introduces the principle of a sensorial threshold. This axiom means that if $B$ is greater than $A$ it has a stochastic advantage of being chosen more often than $A$ in any confrontation with any other bundle $C:^{22}$

21 The difference with Luce's model now appears more clearly. In Luce's model, the threshold in choice is defined as a sensorial threshold only. Georgescu-Roegen (1958, 160) indicates also that Luce's axiomatics of preference is intrinsically discontinuous, whereas the threshold model is inherently stochastic.

22 We may wonder whether this axiom is still compatible with the idea to develop a pure binarychoice model. It implies some structure upon the preference pattern implying three goods. It seems that there is some similarity between this axiom and the WARP. 
"This axiom extends to the threshold in choice a characteristic property of the sensorial threshold: the individual responds to the smallest increase in the difference between two stimuli by an increase in the frequency of right guesses, excepting the case where the difference is such that he always guesses right." (Georgescu-Roegen, $1958,160)$.

And he adds: $p(\mathrm{X}, \mathrm{C})$ is monotonically increasing except when equal to 0 or 1 .

Axiom GR5: If $p(A, B)=p\left(B, C^{\prime}\right)=$ then $p(A, \mathcal{C})=$ It is an axiom of "pseudo-transitivity". The main motivation for this axiom is to avoid passing directly from weak to strong preference, because it would be "in violent contradiction with the very essence of threshold" (Georgescu-Roegen, 1958, 160).

Axiom GR6: If $\boldsymbol{C}^{\prime}=\Lambda A+(1-$ with $\mathrm{O}>\lambda$-then $p(A, \boldsymbol{B}) \leq p(1$

In fact, Georgescu-Roegen presents this axiom as a generalization of the Principle of Persisting Non-Preference, stating that if $p\left(\boldsymbol{C}^{\prime}, \boldsymbol{B}\right):$, then $p(A, \boldsymbol{B}):$ for any $A$ such that $C$ is between $A$ and $B$.

From the set of axioms, the main theorems of interest to us are:

Theorem GR1: It is possible to construct equivalence classes on the basis of the relation of complete indifference $I$ (from theorems 1,2,3 and 4 in GeorgescuRoegen, 1958, 161-162)

Theorem GR2: It is possible to represent the set of indifference classes through a numerical ordering (Georgescu-Roegen, 1958, 162, theorem 5).

Theorem GR3: Any triplet $A, B, C$ satisfies the inequalities:

$$
1 \leq p(A, B)+p(\boldsymbol{B}, \boldsymbol{C})+p 1
$$


As an illustration of the main purpose of the article, Georgescu-Roegen shows that in a two-good case, it is possible to associate to any commodity $A$ in the plan a threshold area delimited by two curves joining in $A$, such that if $B$ belongs to this area (so that $A \mathrm{i} B$ and $B \mathrm{i} A$ ), transitivity is not implied (one can have $C i B$ and $B i A$ but

\section{('l L).}

Another advantage of the model is that it goes well with the idea that distant alternatives (involving important changes in consumption) are more difficult to compare than nearer ones. The widening of the threshold as we move away from A illustrates this.

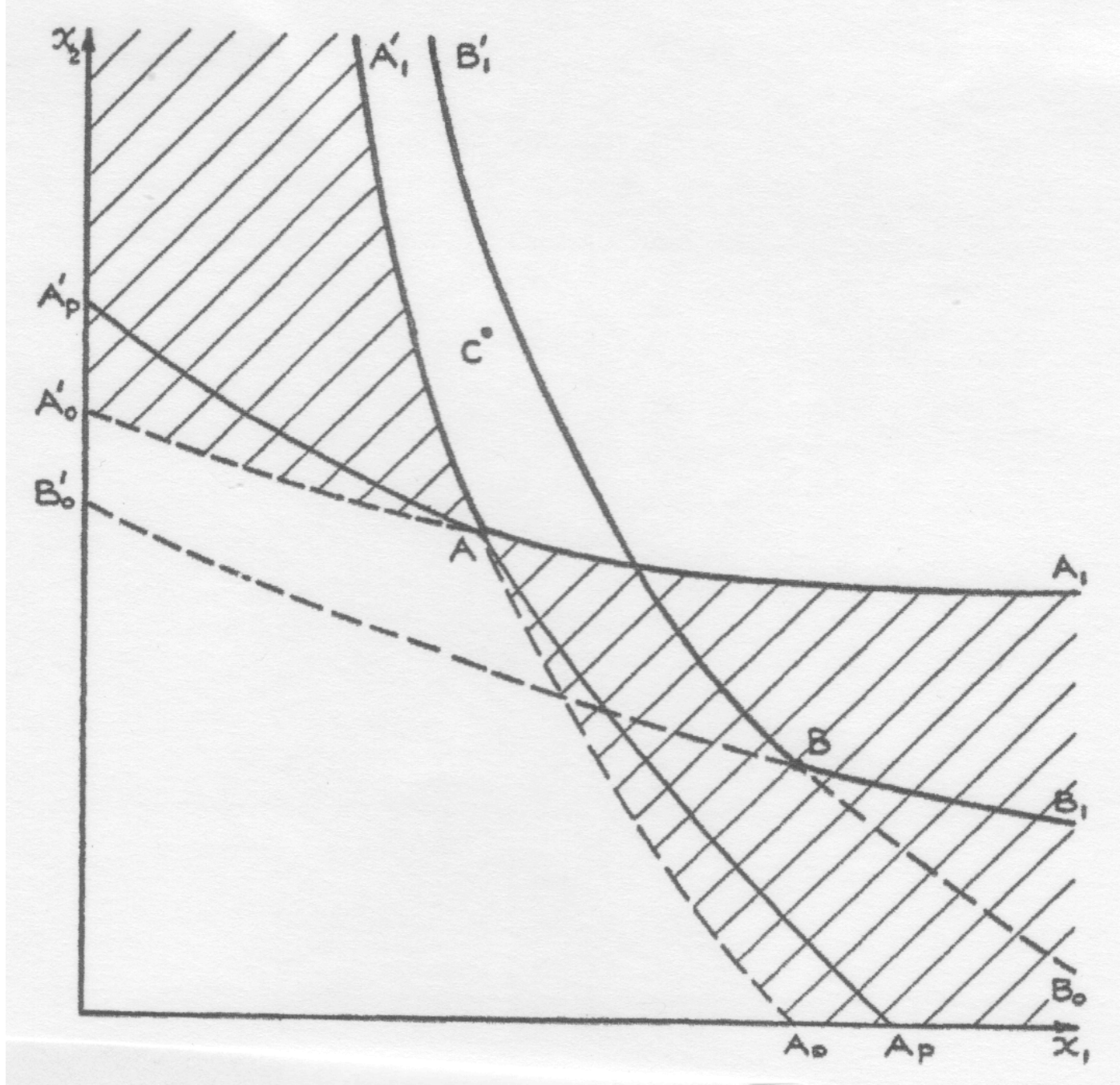


Figure 1 - The threshold of choice (Georgescu-Roegen, 1958)

As a consequence of this axiomatics, Georgescu-Roegen discusses how to obtain a demand penumbra from this binary choice model, expressing the probability that the quantity demanded at some price should lie between $x$ and $x+d x{ }^{23}$ Contrarily with the conclusions of the 1936 paper, he shows that the binary choice model—in its probabilistic setting-does not offer solid enough foundations for obtaining a demand penumbra, and consequently "the only way by which we can arrive at a behavioristic determination of the 'average' demand is to observe the quantities demanded, not the results of binary choices." (Georgescu-Roegen, 1958, 168).

\section{Jacob Marschak: the search for a testable model of probabilistic choice}

Jacob Marschak was no doubt one of the most active theoreticians of the 1950s in the field of rational choice theory. He came back again and again on the subject with different ways to interpret scientific issues and a genuine desire to provide a

${ }^{23}$ This leads to discusing how to obtain information on multiple choice from binary choices. 
comprehensive view on the various theories available. ${ }^{24}$ Notably, he devoted several articles (on his own or co-authored) dealing with alternative models of probabilistic choice. A specificity of Marschak - as compared with Georgescu-Roegen and Quandt - is that he is interested in confronting EUT and OUT (Marschak, 1955, 46). Also, Marschak was well aware of psychologists' work on choice and decision theories and he was particularly interested in devising testable models of choice (Davidson and Marschak, 1959). Last, Marshak is among the few economists who would argue in favor of interpreting rational choice theory as having a prescriptive dimension ("recommendations to be followed" (Marschak, 1950, 111)). ${ }^{25}$

It is not our purpose to provide a complete idea of Marschak's contributions to probabilistic theory of choice. Roughly, in the field of riskless choice, Marschak identified two adjacent issues. On the one hand, one may wonder under what conditions, i.e., under what set of hypotheses on the properties of the probability to choose an alternative among a set of alternatives, probabilistic choice would be representable through a determinate utility function. On the other hand, one may want to weaken the non-probabilistic theory of choice just by "making the ('ordinal') utility function" (Block and Marschak, 1960, 106) a random one. Indeed, Block and Marschak's contribution is usually regarded as the starting point for two ways of modeling probabilistic choice (De Palma and Thisse, 1987) and as a seminal

\footnotetext{
24 Marschak (1950; 1955; 1959), Block and Marschak (1960), Davidson and Marschak (1959).

${ }^{25}$ Marschak is much more assertive in 1955 : "It is important that at least people whose decisions involve the welfare of many others should fulfill certain norms of consistency, should know, for example, how "to make up their minds"" (Marschak, $1955,46)$
} 
contribution (together with Luce, ) on the way to current modeling practices (McFadden, 2001).

In the present article, I shall deal essentially with the first type of problem, the one that is the most in accordance with the problem-situation identified by GeorgescuRoegen and Quandt among others as to the need to make the theory of choice more plausible in terms of psychological foundations and more amenable to empirical testing.

My presentation will be backed on Marschak (1955) and Davidson and Marschak (1959), with occasional references to Marschak (1959) Block and Marschak (1960). ${ }^{26}$ Marschak's model to study habits of behavior is consistently oriented toward constructing a theory of choice with testable implications. This does not mean that any other set of hypotheses shall be dismissed from the outset, but rather that the theoreticians might strive to make a clear distinction between theoretical constructs that are amenable to some type of experimental evidence (from observable choice or verbal statements) and those that are not (or only in an indirect way).

In order to compare a normative theory of behavior with actual observable choices, it is desirable to formulate the model in such a way that comparisons with choices in a laboratory might be possible (and not only comparisons with verbal statements). For this very purpose, probabilistic concepts of choice must be connected with their operational content. Given a set of $n$ alternatives, the first choice $a_{1}$ is always observable, whereas subsequent rankings can be known only through verbal statements of the kind "If $a_{1}$ were not in the alternatives, I would choose $a_{2}$ ".

${ }^{26}$ Block and Marschak (1960) contains most of the content of Marschak (1959). 
Marschak (1955) does not insist so much on the testability of the conditions put on probabilities, even though it deals with a model of binary choices. A special hypothesis of the model, which comes from the operational constraints imposed to it, is that since subjects might be forced to make a decision, indifference and incomparability between two alternatives are excluded from the theoretical setting, at least in a determinate way. Indifference does exist only as a probabilistic statement. Later, Davidson and Marschak underlined different attitudes toward the common experiment of inconsistencies in individual choices.

"One may interpret every case of inconsistency as a case of indifference .... In empirical application, this approach would probably make indifference allpervasive. An alternative approach is to define preference and indifference in terms of probability of choice. In this approach probabilities of choice do not enter the formal axiomatic development. ... [Still another ] strategy, explored in this paper, incorporates probabilities of choice into the axiomatic structures and exploits their properties in scaling utilities" (Davidson and Marschak, 1959, 234)

So, while the first alternative corresponds to Georgescu-Roegen's analysis, Marschak privileges an axiomatic approach that may possibly deliver utility properties from choices.

For instance, Davidson and Marschak (1959) would point later that:

"An important aspect of a general stochastic theory of choice lies in the fact that ... it is possible to obtain forms of measurement stronger than a mere ordering by imposing plausible conditions on probabilities of choice." (Davidson and Marschak, $1959,236)$ 
Let us first define a system of norms on decision. A person is said to behave consistently if she obeys to two norms.

1) If $x$ is chosen rather than $y$, out of a set of larger alternatives, the person shall never choose $y$ rather than $x$ when facing any other set of alternatives.

2) If out of a set comprising $x$ and $y, x$ is chosen and if out of a set comprising $y$ and $z, y$ is chosen, then out of a set comprising $x$ and $z, z$ shall not be chosen.

Decision norms 1) and 2) are implied by four properties: Comparability of outcomes, irrelevance of additional alternatives, constancy of the ordering relation over time, transitivity. ${ }^{27}$ The decision norms 1) and 2) imply that:

i) From successive choices among a finite set of alternatives, by sequentially removing the last chosen alternative in the set, it is possible to obtain a strong ranking of all the alternatives.

ii) From any subset of the original set of alternatives, the same ranking will prevail.

Precisely, Marschak's purpose in a series of articles is to confront decision norms 1) and 2) with empirical decision habits, understood as random variations of behavior around the decision norm, "satisfying certain probability distribution that can be estimated from observations" (Marschak, 1955,48$).{ }^{28}$ The main results obtained can be summarized as follows.

${ }^{27}$ Irrelevance of additional (contextual might be better) alternatives means that whether $x$ is or is not worse than $y$ is independent of whether $z$ (or any other) belongs to the set of alternatives. Transitivity means that if $x$ is not worse than $y$, and $y$ not worse than $z$, then $x$ is not worse than $z$.

${ }^{28}$ This does not prevent from identifying and theorizing the possible implications of observations errors on the part of the experimenter and other variations in the decisional context that might affect the subject's behavior. 
Firstly, it is possible to construct a series of conditions on the probability distributions that will be more or less directly testable and that appear at first sight more or less unrealistic. To each of these conditions, it is possible to attach a specific property on the agent's preferences and, possibly, to identify the properties of the utility function representing those preferences.

From a set of $n$ alternatives, it is possible to obtain $n$ rankings. The basic model, M, tells us that it is possible to identify for each ranking $r_{i}(l=1, .$. a probability that a given subject adopt this ranking, $p_{i}=p($.

A stronger model of choice adds to $\mathrm{M}$ the condition M1 to the effect that i) there is only one maximum for $p_{i}\left(l=1, \ldots\right.$, noted $p_{n}$ and ii) $p_{\text {idecreases as the number }}$ of reversals to obtain $r_{i}$ from $r_{m}$ increases.

A third possible condition M2 to be attributed to agents' behavior (on the $p_{i} \mathrm{~s}$ ) is a property of transitivity in a probabilistic sense. Denote $\mathrm{p}_{x y}$ the probability that alternative $x$ is ranked before $y$ in any possible ranking (by definition, then, $\mathrm{p}_{x y}=1$ $\mathrm{p}_{y x}$ ). The transitivity condition M2 says: for any $x, y, z$, if $p_{x y} \geq$ and $p_{y z} \geq$ then $p_{x z} \geq$. Similarly, indifference is defined by $p_{x y}=p_{y x}$. The transitivity condition is limiting the possible distribution of rankings among alternatives.

Still other conditions might be imposed on the probabilities $p_{i j}$ of ranking the alternatives. For instance, that the probability to rank $x$ before $y$ is the same whatever the number of additional alternatives (M4) or less strongly, that $p_{x y}(x, y)$ when and only when $p_{x y}(x, y, z)(\mathrm{M} 3)$.

Conditions M1-M4 are conditions on random choices. Other possible conditions studied by Marschak are on preference orderings on the different rankings, leading 
to random utility functions. ${ }^{29}$ Conditions M1-M4 constitute a system of possible constraints on the probabilities, from which it is possible to infer some properties of the preference system underlying the choices of an individual and possibly on the kind of random utility indicators likely to represent these preferences (Block and Marschak, 1960).

A few comments are in order about Marschak's approach.

Firstly, aside from the formulation of a probabilistic theory of choice, the most important point is to distinguish those conditions on the probabilities of choice that are directly testable from those that are not, and to draw from this an idea from how much a theory is likely to be supported or not by a class of observations. ${ }^{30}$ On this occasion, one can see that the introduction of verbal statements by the subject about the relative intensities of his preferences might enter into the set of testable conditions, but shall not be given the same status as an observed choice. Whatever the strength of the testable conditions that the theoretician chooses to accept, the main result of Marschak is that it will not be possible to disentangle two different causes of apparently random behavior: A subject might select sometimes $a$ and some other times $b$ when confronted with the set $(a, b)$ either because he does not know all

\footnotetext{
${ }^{29}$ The idea, pioneered by Thurstone (1927) is that to each stimulus $x$ one can ascribe a basic random variable $u(x)$ formalizing all the neural attributes of the stimulus. Each subject is supposed to have some discrimination abilities, expressed by discrimination probabilities, leading to the equation: $p_{x y}=H[u(x)-u(y)]$. Various discussion about the forms of the functions $\mathrm{H}($.$) and \mathrm{u}($.$) were addressed in the$ 1970 's. It also led to various extensions, notably Luce's logistic model (see Luce (1959c)) (see Falmagne (2002, chap.5), de Palma and Thisse (1987), McFadden (2001)).

${ }^{30}$ For instance, binary choices are more easily observable than more complex rankings. Also, the size of the set of alternatives shall not be too large, since some conditions imply a complete simultaneous observation of probabilities on all possible binary choices.
} 
the relevant characteristics of both alternatives in order to make a complete comparison or because both alternatives appear as equally desirable. It might be important to disentangle both causes of behavior if the probabilistic model of choice is to serve as a predictive device (especially when the amount of information is likely to change through repeated choices). The above remark echoes in many respects Georgescu-Roegen's discussion of the threshold model.

Secondly, while discussing testable (necessary but not sufficient) conditions for the existence of a constant utility of the type $v($.$) , that is a function of the Fechnerian$ type, Marschak discusses two conditions on probabilities: Strong transitivity and the Quadruple condition. This is of some importance to appraise Marschak's research agenda, notably as regards the likely comparison between expected utility theory and the probabilistic version of the theory of choice.

Strong transitivity condition: if $p_{i j} \geq$ and $p_{j k} \geq$, then $p_{i k} \geq$ Quadruple condition: if $p_{h i} \geq 1$ then $p_{h j} \geq 1$

Thus, the conditions on $p($.$) are very sensitive for the main outcome of the$ probabilistic choice. ${ }^{31}$ Strong transitivity implies the existence of an ordinal scale of utility whereas the quadruple condition is a necessary but not sufficient condition

${ }^{31}$ Notably, Davidson, Suppes and Siegel $(1957,31)$ have defined a stochastically continuous set of alternatives. Davidson and Marschak (1959) have shown that, stochastic continuity is equivalent to the quadruple condition. Nevertheless, one may wonder whether stochastic continuity is more plausible that the quadruple condition since it assumes condition ii) If $p_{j k}>p_{h i}>\frac{1}{2}$ then $\exists g / p_{j g}>\frac{1}{2}$ ?. See also Debreu (1958). 
for a linear scale of utility. It is to be noted that strong transitivity does not imply a four-stimulus comparison, whereas the quadruple condition does. ${ }^{32}$

In order to provide a test on the existence of a linear utility function, Davidson and Marschak (1959) consider all couples $(i, j)$ such that $p_{i j} \geq$, and they searchamong all possible orderings such that $u(l)-u(j) \geq u(k)-u(l) \geq \ldots \geq$, ([n(n-1)/2]! for the case of $n$ alternatives in a given subset) - those for which $p_{i j} \geq p_{k l} \geq \because$ Then, if there is a subset $T$ on which one necessary and sufficient condition is satisfied, "we then consider confirmation of the existence of a utility function on $T$ as inductive evidence for the existence of a utility function" (Davidson and Marschak, 1959, 240) on a larger subset. Thus, the process of approaching a condition on probabilities for a linear utility function supposes to generalize an empirical property on probabilities from a subset to the whole set of alternatives. From an experimental or empirical perspective, this method is certainly not very attractive, especially if there is a wide variation in the number of alternatives unless one finds a way to combine some tentative statements on utility with surveys on consumers' choices. This may well have been a long run purpose of Marschak:

"Suppose, however, that, in addition to the consumer's survey data, laboratory data are available that imply that choices being made by people of a given socioeconomic group obey certain constraints. The knowledge of these constraints might provide help in further restricting the set of eligible utility indicators" (Marschak, $1959,313)$

32 A weaker transitivity condition is studied by Georgescu-Roegen (1958) and Chipman (1960) 
Thus, in many respects, Marschak's work on probabilistic choice aims at finding conditions on probabilistic behavior and to infer from them the implications of such models for utility analysis.

\section{Quandt's model of probabilistic consumer}

The third and last model of probabilistic choice to be commented in the present study is Quandt's model that was published in 1956 in the Quarterly Journal of Economics. It stands as a rather personal endeavor to provide a model of choice that is based mainly on the idea that the consumer's probabilistic behavior may arise from its need to acquire information. Though Georgescu-Roegen (1936) is undoubtedly the main source of inspiration for Quandt's own venture into probabilistic choice, it is in many respects an original contribution. Compared with Georgescu-Roegen and Marschak's models, it is less involved in an axiomatic reformulation of the theory, nor is it concerned with an experimental testing of individual's rationality. On the contrary, Quandt's "theory" is akin to a modeling of choice, i.e. to the presentation of a model that might be implemented for studying the consumer behavior in face of some specific goods. In this respect, the most striking feature of Quandt's model is to arrive at a classification of goods (and of consumers' strategies attached to it) leading to specific qualitative implications for demand behavior. ${ }^{33}$ This specificity of the model will deserve some comments at the end of the section. Even though Quandt asserts that a number of considerations about consumers' ignorance of their own preferences "make it necessary to revise

\footnotetext{
${ }^{33}$ See also Georgescu-Roegen $(1936,587)$
} 
the theory of preferences and consumer's choice" (Quandt, 1956, 509-10) he arrives at the conclusion that the model "does not replace the traditional theory of the consumer but rather completes it with respect to one of its shortcomings." (Quandt, $1956,536)$

My claim is that Quandt's model is based on a sophisticated criticism of the rationality assumption in economics. Firstly, Quandt questions the axiom of transitivity but also the axiom of comparability goods in the theory of choice. Secondly, he brings to the fore the idea that any choice, even a simple one, is of a strategic nature. From the outset Quandt considers that the consumer is adapting strategically his behavior in front of the situation of choice and the kind of alternatives he can offer. In this respect, Quandt's other source of inspiration is certainly Simon (1955), and the modeling of choice can be read as a bounded rationality model of choice. ${ }^{34}$ Actually, the consumer very often has not experimented with the goods, and he does not even know the method "of finding a set of strategies which will maximize his chances of attaining his goals" (Quandt, 1956, 508). In general, the consumer will not be able to ordering his preferences on the different prospects, either in the small or in the large, and besides he will seldom have an "easily manageable criterion for selecting his optimum strategy", so much so that choice takes place in a context of uncertainty (Quandt, 1956, 509). In order to cope with ignorance, the consumer will adapt his strategic behavior to the kind of

\footnotetext{
34 "The assumption of knowledge and of comparability of alternatives is widespread in economics. The assumption of knowledge is composed of two distinct assumptions. First, it is assumed that the consumer knows the available alternatives. Secondly, it is assumed that he is familiar with the methods of finding a set of strategies which will maximize his chances of attaining his goals." (Quandt, 1956, 508)
} 
information he can gather on those goods. Consequently, Quandt's model deal with a classification of goods according to the level of ignorance and the cost of acquiring information about them. Occasionally, this can lead to conscious randomization of demand behavior:

"Of course, the consumer will hardly be in a state of ignorance with respect to all commodities. The average amount of ignorance concerning a particular commodity depends on the nature of the commodity itself and on the extent to which the consumer can experiment with substitutes and thus acquire information, perhaps through conscious randomization of strategies.“ (Quandt, 1956, 509)

Thus, the main rationale for implementing a probabilistic model of choice is the fact of ignorance, to which the consumer is likely to react through some kind of randomization of choice adapted to the kind of goods that are the objects of choice. As in the case of a mixed strategy in a gaming situation, the consumer will not always make the same choice between A and B over a period of time. This behavior is only contradictory in the surface and can be satisfactorily explained as a strategy for reducing ignorance. Quandt convincingly shows that the recourse to the "subterfuge" that tastes have changed is a flaw of the pure theory. If ever the theory of choice is supposed to help predicting the behavior of an individual over a significant time period, the theory will be stronger if formulated in a probabilistic guise. On this point, one can see an important difference with Georgescu-Roegen. Quandt is searching for a stable concept of tastes, discarding the apparent changes of tastes and the supposed inability of the consumer to express them in a coherent 
fashion. He also discards the usual concept of indifference curves but remains attached to modeling a static theory of consumer's behavior.

In order to account for the consumer's strategic behavior in face of his own ignorance, Quandt proposes to attack the problem through the idea that commodities are in fact representing a set of characteristics. This idea, that would be made popular with Lancaster's new approach to the consumer (Lancaster, 1966), is at the core of Quandt's construction of a probabilistic model of choice:

"Each commodity can be regarded as a collection of what we may call primitive characteristics. Such primitive (or nondecomposable) characteristics are size, weight, color, quantity, suitability for a specific task, etc. It has been stated before that, in general, there is no complete ordering among commodities in the traditional sense. If there is any complete ordering at all, it is, at best, among primitive characteristics. We shall make the weak assumption that there exists a complete ordering among primitive characteristics." (Quandt, 1956, 512)

From earlier studies of intransitive behavior, the reader can easily understand that this assumption will prove crucial for a theory of preferences in which intransitivity may occur.

Any particular commodity $A$ is "described and defined" by a set of "primitive characteristics" $\left(a_{1}, a_{2}, \ldots\right.$ (they might be qualitative or quantitative). Consumer's choice then derives from the application of a utility function to some or all of the characteristics. Each characteristic is liable to contribute in the utility derived from consumption, and Quandt asserts that $i$ ) the consumer knows how each characteristic affects the utility he derives from consuming a certain good, and ii) how much each 
characteristic is contributing to the total utility. The utility function has the following properties:

1) $U$ is continuous

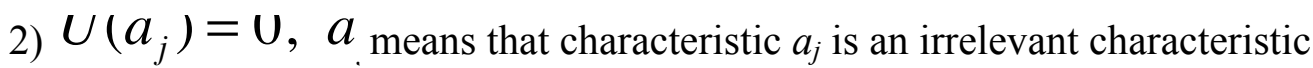

3) $U\left(a_{j}+\Delta a_{j}\right) \geq 1$

4) Any monotonic transformation of $U($.$) is a utility function.$

5) The utility index for commodity $A$ at a particular time is a weighted sum of the $U($.$) over the set of essential 'primitive' characteristics (for instance, r$ among $n$ ) that are always taken into account and of a compound characteristic (taken from the set of 'non-essential' characteristics $n-r)$. Otherwise stated, certain characteristics are less important and are taken into account only occasionally. Total utility then is given by: $\sum_{i=1} w_{i} U\left(a_{i}\right)+w_{j^{\prime}}$

The main consequence is that preferences between $A$ and $B$ may change while tastes are the same:

"All one can really say is that at the time of choice the consumer preferred $A$ to $B$. Since the consumer may base his evaluation of commodities on more or less different sets of characteristics as time passes and external circumstances change, his preference between $A$ and $B$ may change without any change in underlying tastes" (Quandt, 1956, 513). 
Thus, when choosing between $A$ and $B$ the consumer will select a specific list of characteristics for $A$ and $B$ that he considers relevant in given circumstances. When utility attributed to $A$ is larger than utility attributed to $B, A$ is chosen. Thus, in different circumstances, it can be that $B$ is chosen over $A$. The circumstances affecting choice are supposed to be randomly distributed, so that the following definition of preferences follows:

" $A$ is preferred to $B$ if, in the long run, $A$ is chosen over $B$ more than 50 per cent of the time, i.e., if $A$ 's utility index exceeds $B$ 's utility index in more than half the cases in which the consumer has to choose between them;" (Quandt, 1956, 515)

Quandt's model can deal with two different situations. If there is an incomplete scanning of characteristics, choice will be based upon the achievement of a certain level of aspiration, as described by Simon (1955). On the contrary, if all characteristics are accounted for, the behavior may be subject to errors. In either case, the consumer's behavior can be described through a probabilistic model. Notably, Quandt argues that the degree of randomization in the consumer behavior will depend upon the kind of goods under consideration. In the case of durables the consumer gathers a great deal of information before choosing. In the case of daily necessities (representing a small portion of the budget), "experimentation with various brands has virtually no cost and the consumer will soon obtain all the information he needs. ... He experiments and perhaps behaves randomly for a while until learning has taken place" (Quandt, 1956, 518). This behavior may just be subsumed by an even more simple behavior when the cost of acquiring information 
is not worth the benefit, leading to impulsive buying (or equivalently to the "top shelve effect" described by Duesenberry (1949). ${ }^{35}$

The new definition of preference implied by the model makes intransitivity a possible outcome. Quandt's constructs an example with three goods, the utility of each being evaluated through the contribution of a set of characteristics. A joint probability distribution $\mathrm{F}(A, B)$ of pairs of sets of characteristics is constructed, on the assumption that no two sets of characteristics are independently distributed. Then the preference relation $A \mathrm{P} B$ holds if $\int_{\mathrm{U}(\mathrm{A}) \geq \mathrm{U}(\mathrm{B})} \mathrm{dF}(\mathrm{A}, \mathrm{B})>1 / 2$ (identically for $\mathrm{AB}$ and $\mathrm{AC}) .{ }^{36}$

He then constructs different scenarios about the role of each characteristic (reflecting different kinds of external circumstances affecting the relative importance of each characteristics for the consumer), so that intransitivity is likely to occur (Quandt, 1956, Table II, 521). ${ }^{37}$

The main questions are then about the robustness and usefulness of this model.

Firstly, if the circumstances of choice are such that the consumer can get acquainted with the goods through learning (i.e. choosing the best strategy) then one may

${ }^{35}$ This phrasing comes from the fact that in supermarkets, when people are in state of ignorance or hesitation regarding two or more similar products, they buy brands located on the top shelves rather than on bottom shelves.

36 "A is preferred to B (in the present sense of the word "preferred") if the sum of the probabilities of considering pairs of characteristics for which the A characteristic has higher utility is greater than .5" (Quandt, 1956, 522)

37 In the first example, there is a hypothesis of absence of independence, meaning that the characteristics considered as significant for evaluating one commodity will impact the relevant characteristics for the other commodity. In another example, Quandt removes this assumption, and constructs a hypothetical joint probability distribution in the case when there is independency, such that intransitivity holds again (Quandt, 1956, Table III, 522). It is to be noted that in this case, the pattern of probability can exhibit the cases enhanced either by Georgescu-Roegen (that the consumer takes account of all relevant characteristics) or Simon's idea that only some characteristics are taken into account. 
wonder if the model does not vanish into the traditional static model of choice. The answer is negative, so long as the context of choice is open to a continuous change of the environment (e.g. introduction of new substitutes or of new advertising). So, the argument runs, even in the long run, behavior will "continue to be probabilistic and [the consumer's] preferences may be intransitive even in the long run" (Quandt, $1956,525)$.

Secondly, the model allows replacing the traditional indifference curves with isoprobability of choice curves (the same as in Marschak (1955)). And the demand curve is now an "expected demand curve" (Quandt, 1956, 532). In this respect, Quandt is the only one who pushes the development of the model so far in the theory of demand.

Thirdly, the probabilistic model carries some qualitative properties not shared by traditional demand theory. Indeed, as long as a learning process is possible, the demand curve becomes steeper and more inelastic: "This is contrary to the customary hypothesis that in the long run the demand curve tends to become more elastic." (Quandt, 1956, 534). In the traditional analysis, the consumers learn about substitutes, whereas in this analysis, commodities tend to become necessities.

\section{Concluding comments}

The main intuition behind the present study is that the search for a probabilistic theory of choice could not be just a simple transformation from a deterministic model to a stochastic model, since it was motivated from the outset by deep 
theoretical interests for removing some unsatisfying (static) aspects of the HicksAllen theory and, possibly, by grounding the model on testable conditions.

Georgescu-Roegen's article of 1936 opened to a period of questioning of the theory of choice that would become more intense after the development of von Neumann and Morgenstern's theory, so much so that the traditional theory had to do its way between different alternative directions of research. This would lead different scholars to criticize the common representation of choice as a static system of indifference curves, opening the way to different models of probabilistic choice.

Georgescu-Roegen, Marschak and Quandt offer three types of answer to this situation, each of them showing a different attitude towards the role and centrality of the model of choice and its place within the theoretical system of economics.

Marschak brings to the fore the search for some unifying theory of choice, in which decision theory and the Paretian theory of choice can be dealt with in a homogeneous setting. In doing this, he does not question the semantics of preferences. Whatever the reasons for assuming a stochastic behavior, the main stakes are to identify the properties of such a model when one assumes that individual behavior abides by some regularity in terms of probabilistic choice. Marschak's models of random choices and random utilities are conceived of as a general theory of choice between sure prospects. The models are likely to be applied to a wide class of situations. They are also a special case of a wider theory of choice between unsure prospects. In this respect, Marschak's has maintained throughout the idea that imposing some structure on the probabilities of choice will clarify the formal relationships between the expected utility theory and the theory of choice between sure prospects. 
Georgescu-Roegen's main motivation is linked with the instrumental role of the theory of choice for a theory of economic equilibrium. Within a static world, the concepts of preference and indifference are useless, because the conditions for economic equilibrium are given and inalterable. They make sense only in a dynamic world, one in which the economist must be able to account for changes in tastes and preferences through time. The Paretian theory of choice is based on an atemporal conception of preferences. Once one wants to consider that preferences can change and are constantly bound to adapt the flow of innovations and economic transformations, one has to reconsider the concept under some time constraints, thus opening to a change in our understanding and representation of rational behavior, notably about transitivity. In this respect, Georgescu-Roegen's approach can be understood as a new foundation for the theory of choice, even as a new axiomatics of choice.

Quandt's model can be conceived as the result of a deep critic of the Paretian theory of preference, but also of decision theory. For all that, it is not motivated by a search for a new foundation for the theory of choice, since it does not question the use of the model for static economics. Nevertheless, Quandt goes beyond Marschak and Georgescu-Roegen in his search for a unified theory of rational behavior that would systematically rely on a strategic conception of behavior, as a way for human beings to deal with uncertainty about the contingencies of nature. Consequently, the best suited model is likely to change according to the characteristics of uncertainty and the cost of acquiring information for consumers, thus opening potentially a portfolio of models of consumption, depending on the durability and informational characteristics of the goods. 


\section{References}

Alchian, Armen A. (1953) "The Meaning of Utility Measurement", American Economic Review, 43(1) (March), 26-50.

Allen, Roy G. D. (1932) "The Foundations of a Mathematical Theory of Exchange", Economica, 12(2) (May), 197-226.

Armstrong, W. E. (1939) "The Determinateness of the utility Function", Economic Journal, 49(195) (September), 453-467.

Armstrong, W. E. (1948) "Uncertainty and the Utility Function", Economic Journal, 58(229) (March), 1-10

Armstrong, W. E. (1958) "Utility and the 'Ordinalist Fallacy' ", The Review of Economic Studies, 25(3) (June), 172-181. 
Arrow, Kenneth J. (1951a) "Alternative Approaches to the Theory of Choice in Risk-taking Situations", Econometrica, 19(4), (October), 404-37.

Arrow, Kenneth J. (1951b) "Mathematical Models in the Social Sciences", in The Policy Sciences, Recent Developments in Scope and Method, edited by Daniel Lerner and Harold D. Lasswell, 129-154

Arrow, Kenneth J. (1951c) Social Choice and individual values, Cowles Foundation for Research in Economics at Tale University, Monograph 12, Yale University Press.

Arrow, Kenneth J. (1958) "Utilities, Attitudes, Choices: A Review Note", Econometrica, 26(1) (January), 1-23.

Baudin, Louis (1954) "Irrationality in Economics", Quartely Journal of Economics, 68(4) (November), 487-502.

Block, H. D. and Jacob Marschak (1960) "Random Orderings and Stochastic Theories of Responses", Cowles Foundation Paper 147, Reprinted from Contributions to probability and Statistics, edited by Olkinet al., Stanford University Press, 97-132

Bobulescu, Roxana (2017) The Original Time Approach of Georgescu-Roegen. Economia. History, Methodology, Philosophy, 7(1): 87-109.

Boring, Edwin G. (1950) A History of Experimental Psychology, Appleton-CenturyCrofts, Inc., Second edition.

Bush, R. R. and Frederick Mosteller (1951) "A Model for Stimulus Generalization and Discrimination", Psychological Review 58, 413-423

Bush, Robert R., Frederick Mosteller and Gerald L. Thompson (1954) "A Formal Structure for Multiple-Choice Situations", in Thrall et al. (eds.), 99-126. 
Chipman, John S. and Jean-Sébastien Lenfant (2002) "Slutsky's 1915 Article: How It Came to be Found and Interpreted", History of Political Economy, 34(3), 553-597. Chipman, John S., Leonid Hurwicz, Marcel K. Richter and Hugo F. Sonnenschein (eds.) (1971) Preferences, Utility, and Demand, New York: Harcourt Brace Jovanovich.

Churchman, C. West and Philburn Ratoosh (eds.) (1959) Measurement. Definitions and theories, John Wiley \& Sons, Inc.

Coombs, Clyde H. (1959) "Inconsistency of Preferences as a Measure of Psychological Distance", in Churchman and Ratoosh (eds.) (1959), 221-32.

Davidson, Donald and Jacob Marschak (1959) "Experimental Tests of a Stochastic Decision Theory", in Churchman and Ratoosh (1959), (chapter 13), 233-69.

Davidson, Donald, Patrick Suppes and Sidney Siegel (1957) Decision Making. An Experimental Approach, Stanford University Press.

Davis, Robert L. (1954) "Introduction to 'Decision Processes' ", in Thrall et al. (eds.), 1-18.

Deaton, Angus, and John Muellbauer. (1980). Economics and Consumer Behavior. Cambridge (MA) : Cambridge University Press.

Debreu, Gerard (1954) "Representation of a preference ordering by a numerical function", in Thrall et al. (eds.) (1954), 159-165.

Debreu, Gerard (1958) "Stochastic Choice and Cardinal utility", Econometrica, 26(3), 440-444.

Duesenberry, James (1949) "Income-Consumption Relations and Their Implications", in Income, Employment and Public Policy, in Honor of Alvin Hansen. 
Edwards, Ward (1953a) "Comments in the report of the session on 'Individual Preference Functions' " Econometrica, 21(3) (July), 476-7.

Edwards, Ward (1953b) "Probability Preferences in Gambling", American Journal of Psychology, 66, 349-364.

Edwards, Ward (1954) "The Theory of Decision Making", Psychological Bulletin, $51380-417$.

Estes, William K. (1950) "Toward a statistical theory of learning", Psychological Review, 57(2) (March), 94-107.

Falmagne, Jean-Claude (2002) Elements of Psychophysical Theory, Oxford University Press.

Friedman, Milton (1949) "The Marshallian Demand Curve", Journal of Political Economy, 57 (December), 463-95.

Friedman, Milton and Leonard J. Savage (1948) "The Utility Analysis of Choices Involving Risk", Journal of Political Economy, 56, 279-304

Friedman, Milton and Leonard J. Savage (1952) "The Expected-Utility Hypothesis and the Measurability of Utility", Journal of Political Economy, 60, 463-74.

Frisch, Ragnar (1926) "Sur un problème d'économie pure”, Norsk Mathematisk Forenings Skrifter, série I, 16, Grondahl \& Sons Boktrykkeri, Oslo.

Frisch, Ragnar (1932) New Methods of Measuring Marginal Utility, Tübingen, Mohr.

Fullerton, George Stuart. and James McKeen Cattell (1892) On the Perception of Small Differences, University of Pennsylvania Press Publishers.

Georgescu-Roegen, Nicolas (1935) "Note on a Proposition of Pareto", Quarterly Journal of Economics, 49(4) (August), 706-714. 
Georgescu Roegen, Nicholas (1936) "The Pure Theory of Consumer's Behavior", Quarterly Journal of Economics, 50(4) (August), 545-93.

Georgescu-Roegen, Nicholas (1950) "The Constancy of Choice and the Constancy of Economic Laws", Quarterly Journal of Economics, 64(1) (February), 125-138. Georgescu-Roegen, Nicholas (1954) "Choices, Expectations and Measurability", Quarterly Journal of Economics, 68, 503-534.

Georgescu-Roegen, Nicholas (1958) "Threshold in Choice and the Theory of Demand", Econometrica, 26(1), 157-168

Georgescu-Roegen, Nicholas (1969) "The Relation Between binary and multiple choices: some comments and further results", Econometrica, 37, 728-730

Gigerenzer, Gerd (1990) Survival of the Fittest Probabilist: Brunswik, Thurstone, and the Two Disciplines of Psychology. in the Probabilistic Revolution, vol 2.ed. by L. Krüger, G. Gigerenzer and M. S. Morgan, MIT Press, 49-72.

Gilboy, Elizabeth Waterman (1930) Demand curves in theory and practice, QJE, 44, $601-620$

Gilboy, Elizabeth Waterman (1931) The Leontief and Schultz Methods of Deriving 'demand curves', QJE, 45, 218-261

Gulliksen, Harold (1946) "Paired Comparisons and the Logic of Measurement", Psychological Review, 53(3) (May), 199-213.

Hands, D. Wade. 2006. Intergability, Rationalizability, and Path-Dependency in the History of Demand Theory. In Agreement on Demand: Consumer Choice Theory in the $20^{\text {th }}$ Century, D. W. Hands and P. Mirowski (eds.), Durham, NC: Duke University Press [Annual Supplement to volume 38 of History of Political Economy], 153-185. 
Hands, D. Wade. 2011. Back to the Ordinalist Revolution: Behavioral Economic Concerns in Early Modern Consumer Choice Theory. Metroeconomica, 62, 386410.

Hayes, Samuel (1950), "Some Psychological Problems of Economics", Psychological Bulletin, 47(4), 289-330

Heukelom, Floris. 2014. Behavioral Economics: A History. Cambridge: Cambridge University Press.

Hicks, John R. and Roy G. D. Allen (1934) “A Reconsideration of the Theory of Value", Parts 1-2, Economica,n.s. 1 (February), 52-76 and (May) 196-219.

Houthakker, Hendrik S. (1950) "Revealed Preference and the Utility Function", Economica, n.s., 26, 159-174.

Houthakker, Hendrik S. (1961) "The present state of Consumption Theory", Econometrica, 29(4), (October), 704-740.

Katona, George (1951) Psychological Analysis of Economic Behavior, McGrawHill.

Katona, George (1953) "Rational Behavior and Economic Behavior", Psychological Review, 60(5), 307-318.

Lancaster, Kelvin, (1966) "A New Approach to Consumer Theory", Journal of Political Economy, 74, 132-57.

Lenfant, Jean-Sébastien (2012a) "Indifference Curves and the Ordinalist Revolution",

Lenfant, Jean-Sébastien (2012b). Making it up with psychology.

Lewin, K. et al. (1944) "Level of Aspiration," in Personality and the Behavior Disorders, J. McV. Hunt (ed.), New York, 1944, 333-78. 
Luce, R. Duncan (1956) "Semiorders and a Theory of Utility Discrimination", Econometrica, 24(2) (April), 178-191.

Luce, Duncan (1958) “A probabilistic theory of utility”, Econometrica, 26(2) 193224

Luce, R. Duncan (1959a) Individual Choice Behavior, New York, Wiley.

Luce, R. Duncan (1959b) "On the possible psychological laws", Psychological Review, 66(2) (March), 81-95.

Luce, R. Duncan (1959c) “A Probabilistic theory of utility and its relationship to Fechnerian scaling" in Churchman, C. West and Philburn Ratoosh (eds.) (1959) (chapter 7), 144-159

Luce, Duncan and Howard H. Raiffa (1957) Games and Decisions, New York.

Luce, Duncan. 1959.

Luce, Duncan and Ward Edwards (1958) "Derivation of Subjective scales from just noticeable differences", Psychological Review, 65(4), (July), 222-237.

Marschak, Jacob (1950) "Rational Behavior, Uncertain Prospects, and Measurable Utility", Econometrica, 18(2) (April), 111-41

Marschak, Jacob (1955) "Norms and Habits of Decision Making Under Certainty", Mathematical Models of Human Behavior. Proceedings of a Symposium, Dunlap and Associates, Inc., 45-53

Marschak, Jacob (1959) "Binary-Choice Constraints and Random Utility Indicators", Cowles Foundation Paper 155, Reprinted from Mathematical Methods in the Social Sciences, Standford University Press, 1959, 312-329.

May, Kenneth O. (1954) "Intransitivity, Utility, and the Aggregation of Preference Patterns", Econometrica, 22(1) (January), 1-13. 
McFadden, Daniel. 1974. Conditional Logit Analysis of Qualitative Choice Behavior. In Paul Zarembka ed., Frontiers in econometrics. New York: Academic Press, 105-142.

McFadden, Daniel. 2001. Economic Choices. American Economic Review, 91(3): $351-378$.

Modigliani, Franco (1952) "Fluctuations in the Saving-Income Ratio: A Problem in Economic Forecasting", in Studies in Income and Wealth, vol XI, National Bureau of Economic Research.

Mongin, Philippe (2000) "Does Optimization Imply Rationality?", Synthèse, 124, 73-111.

Mongin, Philippe (2003) "L'axiomatique et les theories économiques", revue économique,

Moscati, Ivan (2007) "Early Experiments in Consumer Demand Theory: 19301970", History of Political Economy, 39(3) (Fall), 359-401.

Moscati, Ivan (2016) How Economists Came to Accept Expected Utility Theory: The Case of Samuelson and Savage. Journal of Economic Perspectives, 30(2): 219236

Mosteller, Frederick and Philip Nogee (1951) "An experimental Measurement of Utility", The Journal of Political Economy, 59(5) (October), 371-404.

Neumann, John von and Oskar Morgenstern (1944) Theory of Games and Economic Behavior, Princeton University Press, Third edition, 1953.

Palma, André de et Jacques-François Thisse (1987) "Les modèles de choix discrets", Annales d'économie et de statistique, 9, 151-190 
Papandreou, A. G. (1953) "An experimental Test of an Axiom in the Theory of choice”, Econometrica, 21, 477, (abstract).

Papandreou, A. G., O. H. Sauerlender, O. H. Brownlee, L. Hurwicz and W. Franklin (1957) "A Test of a Stochastic Theory of Choice", University of California Publications in Economics, 16, 1-18.

Pareto, Vilfredo (1909) Manuel d'économie politique, Droz, Genève, 1981. English translation by Ann S. Schwier (from the French Edition of 1926-27) as Manual of Political Economy, Macmillan, 1971.

Quandt, Richard E. (1956) "A Probabilistic Theory of Consumer Behavior", Quarterly Journal of Economics, 70(4) (November), 507-36.

Samuelson, Paul Anthony (1950) "The Problem of Integrability in Utility Theory", Economica, n.s., 17 (November), 355-85.

Schultz, Henry. 1938. The Theory and Measurement of Demand. Chicago: Chicago University Press.

Siegel, Sidney (1957) "Level of aspiration and decision making", Psychological Review, 64(4), 253-262.

Simon, Herbert (1955) "A Behavioral Model of Rational Choice", Quarterly Journal of Economics, 69(1) (February), 99-118.

Simon, Herbert A. (1957) Models of Man. Mathematical essays on Rational Human Behavior in a Social Setting, John Wiley \& Sons, Inc., New York.

Simon, Herbert A. (1959) "Theories of decision-making in economics and behavioral sciences", American Economic Review, 49(3) (June), 253-283.

Stevens, S. S. (1957) "On the Psychophysical Law", Psychological Review, 64(3) (May), 153-181. 
Stevens, S.S. (1959) "Measurement, Psychophysics, and Utility”, in Churchman and Ratoosh (eds.) (1959), 18-64.

Stigler, George J. (1948) "Review of P. A. Samuelson's Foundations of Economic Analysis", Journal of the American Statistical Association, 43, 603-605.

Stigler, George J. (1950) "The Development of Utility Theory", Journal of Political Economy, 58, 307-27, 373-96

Sugden and Bruni. 2007.

Suppes, Patrick (1961) "Behavioristic Foundations of Utility", Econometrica, 29(2) (April), 186-202

Suppes, Patrick and M. Winet (1955) "An Axiomatization of Utility Based on the Notion of Utility Differences", Management Science, 1(3/4) (April-July), 259-70

Thrall, R. M., C. H. Coombs and R. L. Davis (1954) Decision Processes, John Wiley \& Sons, Inc.

Thurstone, Louis Leon. 1927. A law of comparative judgment. Psychological Review, 34, 273-286

Von Neumann, John and Oscar Morgenstern (1944) Theory of Games and Economic Behavior, third edition, 1953, Princeton University Press

Wallis, W. Allen and Milton Friedman (1942) "The Empirical Derivation of Indifference Functions", in Studies in Mathematical Economics and Econometrics: In Memory of Henry Schultz, edited by Oscar Lange, F. McIntyre and T. O. Yntema. Chicago, Chicago University Press. 175-189.

Wold, Herman O. A. (1943-44) "A Synthesis of Pure Demand Analysis. I, II, III", SkandinaviskAktuarietidskrift, 26: 85-118, 220-63; 27: 69-120. 
Wold, Herman O. A. (1952) "Ordinal preferences or Cardinal Uitlity", Econometrica, 20(4), (October), 661-64 